\title{
Prevention of Economic Losses with the help of the System of Control of Saving and Storing Bulk Cargoes in the Process of Train Movement
}

\author{
Vitalyi Sakhatsky ${ }^{1}$, Nina Lyubymova ${ }^{2}$, Vladimir Pusik ${ }^{2}$, Luydmila Pusik ${ }^{2}$, and Ievhenii \\ Chepusenko $^{1}$ \\ ${ }^{1}$ Kharkiv National Automobile and Highway University, Yaroslava Mudrogo str., 25, Kharkiv, Ukraine, 61002
${ }^{2}$ Kharkiv Petro Vasylenko National Technical University of Agriculture, Alchevskykh str., 44, Kharkiv, Ukraine,
61000
}

\begin{abstract}
In order to ensure the demand of the market for competitive rail transport services, the structure of automatic safety control for bulk cargo is proposed on the basis of the radar sensor and Wi-Fi technology, which allows to avoid the false alert signal caused by changes in the level of liquid due to various deviations of the railway track from the horizontal plane and to fix leakage of the liquid from damaged tank. The issues of increasing the reliability of the proposed control system are considered.
\end{abstract}

The economic effect of the railway transport system in many respects is determined by higher speed and volume of traffic, traffic safety during the delivery of goods to the consumer $[1,2,3]$. In [4] it is noted that with a modern traffic safety management system, a further increase in traffic volume by $20-30 \%$ can lead to an increase in traffic safety violations by $40-80 \%$. The amount of losses from traffic accidents in Ukraine in 1996 amounted to about UAH 40,000 thousand. In 2006 it was about UAH 22,000 thousand, and in $2014-$ UAH 7,525 thousand [2]. According to [5], the main causes of emergency situations include increased traffic flow density, failures in the operation of technical means, and untimely prevention of causes of defects. To reduce losses, economic methods of traffic safety management should be used which involve technical audit, a comprehensive assessment of railway transport, non-destructive monitoring and diagnostics [6]. Improving the safety and reliability of rail transport provides a reduction in the level of real transport costs in the price of products by $30 \%$ and an increase in the productivity of rail transport by $2-4$ times [7].

A significant part of freight traffic falls on bulk cargo that is transported in tanks, in bunker open car and special containers. Bulk cargoes are divided into hazardous and nonhazardous. Dangerous goods are transported in special packages in covered cars and containers, liquefied gases and chemical goods are transported in specialized tanks. Any malfunction of the tank can lead to leakage of bulk cargoes in transit, which causes a threat to traffic safety and economic damage to both the railway and the owners of the cargo. Therefore, when damage to the tank is detected, it is detached from the train and transported to a safe place. The safety of the bulk cargo is usually checked during its loading and unloading [8].

In [9], it was stated that "one of the strategic directions for the development of rail transport is the creation of a technical diagnostics system with increased reliability of defect detection and predictive diagnostic systems based on fundamentally new ways to detect 
defects when a train is moving". In industry, many methods for controlling the level of fluid are used: buoyancy, visual, hydrostatic, float, electric, radio-wave, magnetostrictive, ultrasonic and others [10]. In railway transport, when monitoring the level of oil products in tanks, the measuring rod is widely used as a measuring tool. It is used, for example, to measure the level of fuel oil and the level of commercial water [11], as well as other bulk cargoes. However, this method of monitoring the status of bulk cargo is unacceptable when the train moves.

In [12] an ultrasonic level gauge is presented, which is used to measure the level of liquid substances in railway tanks. It is intended for solving problems of automation of loss control of bulk cargoes on railways, control of loading and unloading. When these sensors are used, information about the damage to railway systems or the leakage of liquid cargo from tanks can be obtained early and thereby train traffic safety is increased.

To monitor and record various parameters of liquids through the wall of tanks and closed tanks, Ultrasic Advanced Technologies LLC has developed ultrasonic level analyzing gauges for liquids: ANALIQ-M and ANALIQ-S. The devices can measure the level, mass, volume, density of various liquids (oil products, liquefied gases, oils, acids, alkalis, alcohols, poisonous liquids, etc.) that are in tanks, barrels, cylinders and other closed tanks. Level measurement range from $3 \mathrm{~cm}$ to $50 \mathrm{~m}$ with an error of $\pm 1 \mathrm{~mm}$. Video presentation of the operation of ANALIQ-M is presented in [13].

A promising method for measuring the level of a liquid is the radio wave method, the kind of which is the radar method $[14,15]$. It is based on the measured time of passing the radio signal of a double distance from the emitter to the surface of the liquid.

For example, the Rosemount Radar Sensor Series 5600 allows measuring the level of such media as petroleum products, suspensions, solvents, aqueous solutions, cement, and fine particulate powder materials [16].

A principle of the method for determining the level of liquid of all radar gauges is that the surface of the reflection is taken over the surface of the liquid and the level of the liquid is identified by determining the time of propagation of the signal from the antenna to the surface of the liquid. This is quite true for dielectric environments and needs to be clarified for conductive media. Scientific works devoted to the question of reflecting radio waves from conducting media showed that for such media there is an effective reflection surface that does not coincide with the actual surface of the liquid [17]. Therefore, the result of measuring such a liquid with radar will have a methodological error, which has not been studied to date.

Therefore, the creation and improvement of reliability of radar methods and automatic safety control systems for a wide class of bulk cargoes is an urgent task.

The purpose of the work is to reduce economic losses by improving the safety of transportation of bulk cargoes using an automatic system for monitoring their safety.

We define the requirements that apply to the developed control system.

Currently, the railway transport uses a variety of security systems. They are based on the known technologies such as Ethernet, CAN, RS-485. Systems using radio signals, such as GPS/GLONASS, GSM-R, Wi-Fi and others, are being developed and implemented. The modern infrastructure of the train includes various systems: the CLUB-U system, which ensures the safety of the train on the hauls by monitoring the exceeding of the permissible speed and braking, recording the motion parameters, the diagnostic system, the wheel pair monitoring system, the locomotive telemetry system.

When monitoring the level of liquid goods when the train moves, information should be transmitted from the level sensors to the liquid level indication system in real time. In this case, if the tank or other container is damaged and the fluid leaks, the control and measurement system will timely generate an alarm signal. If the railway track has angles of deviation from the horizontal plane, the level of the liquid in the tank at the installation site 
of the level sensor will also change, which can cause a false alarm. To prevent such an effect, additional information is required that the change in the level of the liquid is due to a spatial change in the trajectory of the railway, and not a leak. Therefore, one of the controlled parameters should be the angle of inclination of the railway track relative to the horizontal plane.

Let us consider the structure and principle of operation of the automatic system for monitoring the safety of liquid cargo.

To determine the spatial position of various objects, use special inertial systems. Such systems may include an accelerometer, gyroscope and magnetometer. The accelerometer is used to measure linear accelerations, the gyroscope is for angular, the magnetometer measures the Earth's magnetic field and is used to determine the angle in azimuth. By combining these three sensors in one device, we get a complex system for determining the spatial position of the object.

Installing such a device directly on the locomotive will help determine the angles of inclination of the railroad bed relative to the horizontal plane during train movement and eliminate the false alarm signal.

One such device could be the BMX 055 sensor from Bosch Sensor tec. The BMX 055 sensor contains three high-precision and diverse three-axis sensors: a 12-bit low-noise accelerometer, a 16-bit gyroscope with programmable measurement ranges, and a low-noise wide-range geomagnetic sensor optimized to achieve a better performance/power ratio. Incorporating all of these devices, the BMX055 Absolute Orientation Sensor provides detection of acceleration, angular velocity, and geomagnetic measurements.

When choosing the means and method of transferring measurement information to the operator, the following was taken into account. To reduce the effects of electromagnetic interference in the transmission of information the most suitable is the range of the microwave.

Wi-Fi technology works at a frequency of 2400-2483.5 MHz, according to the IEEE 802.11 standard. One of the Wi-Fi modules that operates at $2.4 \mathrm{GHz}$ is ESP-07S. It includes a microcontroller and a radio transmitter at the same time, which is a big advantage.

Wi-Fi ESP-07S module supports the standard IEEE802.11b/g/n protocol with WEP / WPA-PSK/WPA2-PSK security modes, supports network and packet protocols: IPv4, TCP / UDP / HTTP / FTP. It can function in three modes: client, access point, client + access point. Interface support: UART, GPIO, I2C, I2. SDIO, PWM, ADC, SPI. The transmitting device acts as a client and consists of a Wi-Fi module ESP-07S and a position sensor BMX055. The BMX055 sensor connects to the ESP-07S and communicates with it via the I2C protocol.

The ESP-07S module reads data from the BMX055 sensor registers for each of the axes of a 3-axis accelerometer, 3-axis gyroscope and a 3-axis magnetometer, processes the embedded microprocessor and transmits the processed information through a wire transmission line to the receiver.

The Wi-Fi module ESP-07S, which is configured as an access point, also acts as a receiver. This module is located in the locomotive driver's cab. The received information signal from the transmitter is displayed to the operator.

The block diagram of the measuring system for determining the parameters of the spatial position of the railway track is shown in Fig. 1. 


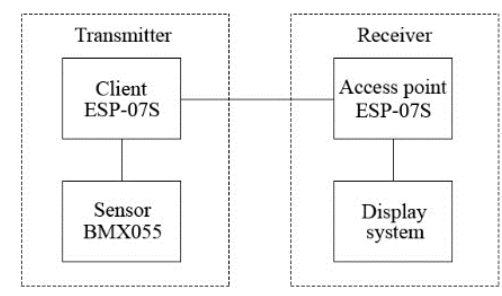

Fig. 1. Block diagram of the measuring system for determining the spatial position of the railway track.

The occurrence of leakage of fluid from the tank (tank) can be controlled using an additional data transmission system from a radar level gauge. Such a system, for example, can be implemented on the basis of devices developed by EMERSON, which is produced by the Industrial Group METRAN (Chelyabinsk, Russia) [18]. A Rosemount 5400 Series Radar Transmitter with a HART / 4-20mA output signal can be used as a sensor. The model of the radar of this series 5401 operates at a frequency of $6 \mathrm{GHz}$, and the model 5402 - at $26 \mathrm{GHz}$. A distinctive feature of the radar is the use of circular polarization of the wave, which allows increasing the measurement reliability by reducing by $50 \%$ the number of echo signals from the internal structures of the reservoir.

To transmit information over a wireless protocol, Wireless HART, you must connect a Rosemount 775 converter to the sensor, which is designed to transmit data from any wired sensor that has a HART / 4-20 mA output signal. The Rosemount 775 converter transmits data to the Rosemount 1420 wireless gateway, which allows the integration of a measuring device (gauge) into the Smart Wireless wireless network, as well as remote configuration of devices.

The 1420 Wireless Gateway connects Smart Wireless networks to any higher level. Data transmission is carried out via Modbus protocol via RS 485 interface or local Ethernet network, which are available on modern trains. Reception and transmission of data is carried out at the operating frequency of $2.4-2.4835 \mathrm{GHz}$ via Wireless HART protocol. The Rosemount 1420 Gateway is the entry point for data transmission to the operator and can support up to 100 level gauges simultaneously.

During transportation of liquid cargo, the accuracy of the information transmitted from the liquid level sensors is of paramount importance.

Let us estimate the methodological error that occurs when measuring the level of conductive liquids. We choose three well-known fluids - hydrogen iodide (HI), for which $\sigma=$ $10630 \mathrm{~cm} / \mathrm{m}, \boldsymbol{\varepsilon}_{r}=2.9$; nitric acid $\left(\mathrm{HNO}_{3}\right)$, for which $\sigma=1.5 \mathrm{~cm} / \mathrm{m}, \boldsymbol{\varepsilon}_{r}=1.77$ and sodium chloride $(\mathrm{NaCl})$, for which $\sigma=3.4 \mathrm{~cm} / \mathrm{m}, \varepsilon_{r}=6.3[19]$.

According to the method of equivalent mirror reflection for media with finite conductivity, the time taken to receive a reflected pulse increases (is delayed) for the time they pass the distance [17]:

$$
d_{E}=\frac{-j \lambda}{\pi \sqrt{\left(\varepsilon_{r}-1\right)-j 60 \sigma \lambda}},
$$

which causes a methodological error when measuring the level of conductive fluid.

In [20] it was shown that the group velocity of propagation of a radio pulse in a medium at frequency can be represented through the derivative of the complex wave number $\gamma^{l}(\omega)$ as follows

$$
V_{z p}=1 / \gamma^{l}(\omega),
$$




$$
\gamma^{\prime}=\frac{1}{300}\left[\frac{1\left(2 \omega \varepsilon_{r}-j 36000 \pi \sigma\right.}{2 \sqrt{\varepsilon_{r} \omega^{2}-j 36000 \pi \omega}}\right]
$$

In this case, $\omega$ is the maximum frequency of the spectrum of the radio pulse [21]. Then the delay time of the reflected liquid from the radiation is equal:

$$
\Delta t=\frac{d_{E}}{V_{2 p}},
$$

When finding the distance to the surface of the liquid, the radar computational system does not take into account the full path of radio signal passage from its moment of radiation to the moment of its reception, but only half of this path, then the unregarded thickness of the liquid layer (methodical error of measurement), which is located above the equivalent surface of reflection, is determined by the following way:

$$
h=\operatorname{Re} \Delta t \cdot c / 2 \text {, }
$$

where $c$ is the speed of light.

Since the level levels of the liquid level in most of them operate in the frequency range from $5 \mathrm{GHz}$ to $25 \mathrm{GHz}$, the delay time was determined for the frequencies of this range with a pulse duration $\tau_{i}=10 \mu \mathrm{s}$.

The results of the calculation showed that for the selected fluids, the methodical error does not exceed $7.1 \mathrm{~mm}$, which is higher than the accuracy of high-precision radar for measuring the level of dielectric liquids, which is equal to $\pm 1 \mathrm{~mm}$. This error is systematic and should therefore be taken into account as an integral part of other errors in the level meter, which will provide greater reliability of measurement.

\section{Findings}

According to the results of the research the following conclusions can be drawn. A structure for designing a control and measuring system for the preservation of bulk cargoes is proposed. It consists of two subsystems: the subsystem for measuring the level of liquid in the tank and the subsystem for monitoring a false alarm signal that occurs when the railroad tracks deviate from the horizontal axis.

The choice of the element base of the system on the basis of devices that are produced in industry has been made.

This allows reducing the cost of production of the proposed control and measuring system by eliminating the need to develop special components and elements of the system.

The features of the interaction of radiation from radar sensors with conducting fluids are investigated. It is shown that the presence of fluid conductivity causes the appearance of a methodological error in measuring its level, which may exceed the known errors of radar sensors.

Is this error is taken into account the reliability of the control and measuring system as a whole increases.

\section{References}

1. Transportna strategiya Ukrayini na period do 2020 roku URL: http://zakon4.rada.gov.ua/laws/show/2174-2010-p. 
2. A.I. Ogar, Yu.O. Pazoyskiy, A.V. Rozsoha, A.A. Sidrakov, Yu.V. Smagilo ZbIrnik naukovih prats UkrDUZT, 156, 18-28 (2015).

3. Rasporyazhenie OAO RZhD \# 987r ot 29.05.07 «Funktsionalnaya strategiya obespecheniya garantirovannoy bezopasnosti i nadezhnosti perevozochnogo protsessa OAO RZhD.-115c.

4. O.S. Burch. Vestnik nauki Sibiri. 1 (7), 139-146, (2013)

5. V.A. Olentsevich, V.E. Gozbenko. Sovremennyie tehnologii. Sistemnyiy analiz. Modelirovanie. 1 (37), 87-90, (2013)

6. V.I. Yakunina. Zheleznodorozhnyiy transport, 1, 2-11, (2009)

7. A.N. Golovash Problemyi sovremennoy ekonomiki, 14, 378-382, (2010)

8. V.P. Perepon Organizatsiya perevozok gruzov: Uchebnik dlya tehnikumov i kollezhdey zheleznodorozhnogo transporta, M.: Marshrut, 614, (2003)

9. Strategiya razvitiya zheleznodorozhnogo transporta v RF do 2030 goda Utverzhdena Rasporyazheniem Pravitelstva RF ot 17 iyunya 2008 g. \# 877- [Elektronnyiy resurs]. Rezhim dostupa: http://www.mintrans.ru/documents/detail.phpELEMENT ID=13009

10. V. E. Nazarov Analiz suchasnogo stanu metodiv $i$ zasobIv vimIryuvalnogo kontrolyu rivnya ridinnih seredovisch :navch. posIb. severodonetsk: NU Im. V. Dalya, 114, (2016)

11. Gost R8.787-2012 Gosudarstvennaya sistema obespecheniya edinstva izmereniy (GSI). Massa mazuta. Metodika izmereniy v zheleznodorozhnyih tsisternah. Obschie metrologicheskie trebovaniya.

12. I.P. Merkulova , P.A. Shirokolobova, V.A. Olentsevich. Molodaya nauka Sibiri: elektron. nauchn. zhurn. 2, ( 2018), URL: http: // mnv.irgups.ru/toma/22-2018,

13. Video prezentatsiya rabotyi ANALIQ-M URL: http://www.yotube.com/watch.v.hLcbLzntyLk

14. V. K. Zhdankin Priboryi dlya izmereniya urovnya: ucheb. posob. M.: STA-PRESS, 19, (2002).

15. N. G. Farzane Tehnologicheskie izmereniya i priboryi :navch. posIb. M. : Vyissh. shkola, 456, (1989)

16. Kompaniya Emerson Process Management i Promyishlennoy gruppyi «Metran». Urovnemeryi. Moskva, 16, 206, (2011), URL: :https://www.emerson.com/documents/automation/уровнемеры-каталог-ru61704.pdf

17. P. R. Banister. RadioScience, 17.5,1095-1102, (1982)

18. Urovnemeryi- $\quad$ Vyipusk $\quad 2018 \quad-\quad$ Emerson

URL:https://www.emerson.com/documents/automation/catalog-уровнемеры-каталогmetran-ru

19. B. P. Nikolskiy Osnovnyie svoystva neorganicheskih $i$ organicheskih soedineniy. Spravochnik himika. M.:Himiya , 2, 1169. (1971)

20. E.S Birger., L. A. Vaynshteyn. Tehnicheskaya fizika. 11, 2217- 2228, (1973)

21. G.I.Tyorina. Radiotehnika i elektronika. 9, 611- 613, (1971) 